\title{
Protestantismo de imigração: Chegada e reorientação teológica ${ }^{1}$
}

\author{
Antonio Carlos Ribeiro
}

\section{Introdução}

Ao celebrar os 180 anos de presença luterana no Rio de Janeiro (25.06.1827 - 25.06.2007) ocorreu-me refletir sobre dois momentos significativos dessa história: a chegada dos imigrantes e a reorientação teológica. A primeira por causa das condições políticas que a favoreceram, e a segunda, por causa da contribuição de Karl Barth a respeito da atuação pastoral com o germanismo.

O século começou com a chegada da Corte Portuguesa em 1808, tendo à frente o Príncipe Regente e a Rainha louca, fato que alterou a vida da cidade que já era sede dos Vice-reis de Portugal, com a instalação do aparelho estatal, que se fez seguir pela cultura, as artes, os poderes político e econômico, e pelo surgimento da Imprensa Régia. A proximidade do poder gerou a disputa entre a perspectiva religiosa e a política liberal, influenciada pela Inglaterra. O país era constitucionalmente católico, mas o rei liberal, mantendo sua autonomia na administração pública.

\footnotetext{
${ }^{1}$ Excertos da Dissertação de Mestrado em Teologia - Como cantar a Canção do Senhor?; Desafios ao testemunho da Igreja Evangélica de Confissão Luterana no Brasil nos centros urbanos da atualidade, orientada pela Prof. ${ }^{a}$ Ana Maria Tepedino, defendida em 12.12.2005 na PUC-Rio e apresentados como comunicação no II Simpósio Internacional de Teologia e Ciências da Religião, realizado de 11 a 13 de setembro na Universidade católica de Pernambuco (UNICAP).
} 


\section{Brasil: país católico e liberal recebe protestante}

A vinda da tradicional corte portuguesa católica para a colônia do Brasil nos primórdios do século XIX é o fato mais relevante para compreendermos o pano de fundo no qual se dará o início da imigração de colonos alemães luteranos ainda no primeiro quartel deste século. A fuga da família real, após a ocupação de Portugal por Napoleão em $1808^{2}$, é a explicação determinante para a sua presença numa terra até então com pouca importância política, mesmo três séculos após seu descobrimento e um aparentemente inesgotável empreendimento econômico de exploração mineral.

A transferência da corte implica uma nova configuração nas relações de poder político e religioso, já iniciada com a transferência da Sede dos Vice-Reis do Brasil da cidade de Salvador para a cidade do Rio de Janeiro ${ }^{3}$, acentuando-se ao ponto de tornar o Brasil um centro de convergência dos interesses portugueses, especialmente nas possessões no Estado do GrãoPará, no Estado Maranhão e Piauí e no Estado do Brasil, entre outras unidades menores ${ }^{4}$.

Apenas em "meados do século XVIII que se tornou evidente ter-se transformado o Brasil em peça mestra dos domínios lusos, superando a própria metrópole em peso econômico e demográfico" ${ }^{\text {, }}$, portanto excessivamente tarde e então sob pressão dos fatos políticos da Europa. Os portugueses ainda se mostraram incapazes de perceber que a principal conseqüência desse fato era a separação entre a América portuguesa e a metrópole, absorvidos na tendência de apropriarem-se das possessões do novo mundo como fonte inesgotável e da extorsão de recursos fiscais, feitos das maneiras mais variadas e através de escandaloso arbítrio.

Para o Rio de Janeiro a presença da corte portuguesa significa uma revolução sócio-econômico-cultural. Entre as principais realizações destacamse a criação de escolas primárias e secundárias, da Academia de Artes, de Bibliotecas, de Museus, da Imprensa Régia e da exploração das riquezas

\footnotetext{
2 "Com a invasão de Portugal por tropas francesas, o príncipe-regente João, acompanhado de sua corte e sob proteção de barcos ingleses, deixou Lisboa em novembro de 1807, chegando à Bahia em 22 de janeiro de 1808 e ao Rio de Janeiro, onde se instalaria por treze anos, em 7 de março de 1808. Com o príncipe vinha a rainha louca, Maria, e talvez 15 mil pessoas em uma vintena de barcos. Com a instalação da corte e do governo de Portugal no Rio o Brasil deixou, na prática e definitivamente, de ser uma colônia". CARDOSO, C. F. S. A crise do colonialismo luso na América Portuguesa - 1750-1822. In: LINHARES, M. Y., org. História Geral do Brasil. 6. Ed. Rio de Janeiro: Campus, 1996, p. 118.

${ }^{3}$ A transferência acontece em 27 de janeiro de 1763.

${ }^{4}$ CARDOSO, C. F. S. Op. cit., p. 102.

${ }^{5}$ Ibid.
} 
naturais. "Um verdadeiro aparelho de Estado e um corpo diplomático instalaram-se no Rio ${ }^{6}$. Tantos avanços políticos e econômicos levaram D. João a proclamar a criação do Reino Unido de Portugal, Brasil e Algarve7. "A excapital colonial tornara-se sede de ministérios, secretarias, tribunais, repartições públicas, de um Conselho de Estado, outro de Fazenda etc. E foi no Rio de Janeiro que, morta a rainha, o até então príncipe-regente foi aclamado, em

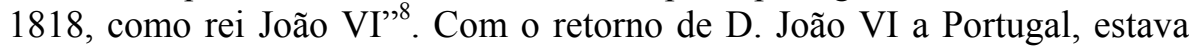
dado o passo decisivo para o aprofundamento da ruptura, caminho aberto para a Proclamação da Independência ${ }^{9}$.

O significado desse conjunto de fatos, que em apenas 14 anos culminaram na Independência do Brasil, é semelhante ao ocorrido em toda a América espanhola: eles agravaram os riscos do universalismo católico. Ao dar importância ao galicanismo histórico ${ }^{10}$ e ter sido "formado sob o clima liberal, o Império não levava muito em conta as prerrogativas da Igreja e cerceava mesmo seus esforços anti-liberalizantes através de mecanismos legais do direito de padroado", tendo certo resultado para a vida religiosa ${ }^{11}$.

A resposta da Igreja ao papel que lhe foi concedido pelos primórdios do reinado no Brasil utilizou basicamente duas formas de penetração e reforço de seu poder hegemônico. A primeira, de natureza político-eclesiástica, foi ampliar o sistema de nunciaturas a partir do Papa Gregório XVI ${ }^{12}$. Além

\footnotetext{
${ }^{6}$ Ibid., p. 118.

${ }^{7}$ A proclamação foi feita em 16 de dezembro de 1815 , apenas sete anos após a chegada da família real.

${ }^{8}$ CARDOSO, C. F. S. Op. cit., p. 118. "Salvador, até então a maior cidade brasileira, foi superada pelo Rio por volta de 1810. A população dessa última capital chegou a aproximadamente 113 mil pessoas em 1819". "O Brasil, às vésperas de separar-se de Portugal, continuava sendo, apesar de tudo, estruturalmente uma sociedade colonial. Em 1818, de seus 3.817 .900 habitantes, 1.887.900 eram livres (sendo 1.043 .000 brancos, 585.500 negros e mestiços, 259.400 índios e 1.930 .000 escravos). Ibid., p. 119-20.

${ }^{9}$ Poucos anos depois, em 1821, D. João se viu obrigado a retornar a Portugal, deixando seu filho Pedro como Príncipe Regente. A manutenção da instabilidade política levou à ruptura definitiva dos laços institucionais e dos vínculos políticos com Portugal, fato que teve como conseqüência a Proclamação da Independência em 7 de setembro de 1822 e a proclamação do primeiro imperador, D. Pedro I. DREHER, M. N. Igreja e Germanidade; estudo crítico da história da Igreja Evangélica de Confissão Luterana no Brasil. São Leopoldo: Sinodal; Porto Alegre: EST São Lourenço de Brindes; Caxias do Sul: EDUCS, 1984, p. 23.

${ }^{10}$ Tendência jurídica e teológica que defendia, no século XIV, a interferência dos reis franceses nos negócios eclesiásticos, e mais tarde, após o século XVII, a autonomia dos bispos franceses em face da autoridade pontifícia romana, opondo-se ao ultramontanismo.

${ }^{11}$ MENDONÇA, A. G. Inserção dos Protestantismos e "Questão religiosa" no Brasil, Século XIX (Reflexões e hipóteses). Estudos Teológicos/EST, 1987/27 (3): 226.

${ }^{12}$ A nunciatura brasileira é uma das mais antigas da América Latina (1830), havendo momentos em que houve internunciaturas sediadas no Brasil, com jurisdição para toda ou parte da
} 
do aperfeiçoamento do relacionamento entre o Estado Pontifício e os Estados nacionais, através dos núncios, foram adotadas medidas como a retomada das visitas ad limina e a elevação de clérigos à prelatura. A segunda, de traço mais propriamente religiosa, foi a cruzada doutrinária contra "os erros do mundo moderno" através do Concílio Ecumênico convocado pelo Papa Pio IX para dezembro de $1869^{13}$.

O Concílio refletia o conflito entre o espírito do mundo latino e o mundo anglo-saxão, a mesma tensão vivida pelo império brasileiro, com a disputa hegemônica entre essas duas culturas. Ao mesmo tempo no Brasil, especialmente no Rio de Janeiro, predominava intensa e visivelmente uma admiração pelo mundo anglo-saxão. E não era apenas alguns sinais de antiga dependência política, como a vivida com Portugal, mas envolvia certo discipulado filosófico e a adoção de certos modelos progressistas da Inglaterra e dos Estados Unidos ${ }^{14}$.

Por colocar-se exatamente no cruzamento das perspectivas teológicas, jurídicas e filosóficas de uma sociedade em busca de definição dos seus rumos, a questão religiosa é a expressão brasileira da grande luta entre a Igreja e o mundo libera ${ }^{15}$. Anos antes da deflagração do conflito entre os bispos e o Imperador, o episcopado brasileiro vinha tendo confrontos com o pensamento liberal e o regalismo ${ }^{16}$ imperial. $\mathrm{O}$ confronto se acentuava à medida que as alas tradicionais, conservadora e romanista da Igreja tinham dificuldades com o avanço das idéias liberais, e os intelectuais e políticos liberais do Império mostravam-se despreocupados, já que sem o placet do Imperador nenhuma decisão ou instrução de Roma entraria em vigor ${ }^{17}$.

América Latina, veja PRIEN, H.-J. La Historia del Cristianismo en America Latina. Salamanca: Sígueme; São Leopoldo: Sinodal, 1985, p. 401, apud MENDONÇA, A. G. Op. cit.

${ }^{13} \mathrm{O}$ Concílio reunido em 08.12 .1869 era composto de 700 bispos e predominantemente latino. A ênfase era o princípio da autoridade do Papa sobre as igrejas nacionais, acima dos respectivos governos, num mundo minado pelas aspirações democráticas próximas da anarquia revolucionária, cuja fonte principal acreditava encontrar-se no protestantismo. AUBERT, R. Nova História da Igreja. Petrópolis: Vozes, 1975, v. 1, p. 64. A Assembléia foi suspensa prematuramente em 20.10.1870, mas conseguiu votar e aprovar proposições que provocaram reações em setores importantes da própria Igreja e no mundo liberal.

14 "As mais ativas mentes brasileiras tomaram partido, senão contra a Igreja como expressão religiosa, pelo menos como instituição portadora do espírito anti-liberal e anti-progressista. MENDONÇA, A. G. Op. cit., p. 227.

${ }^{15}$ Sobre este ponto ver FRAGOSO, H. A Igreja-instituição. In: História da Igreja no Brasil. Petrópolis: Vozes, 1980, tomo II/2, p. 186.

${ }^{16}$ Doutrina que defende a ingerência do chefe de Estado em questões religiosas.

${ }^{17}$ MENDONÇA, A. G. Op. cit. 
A questão religiosa deixa suas marcas no campo religioso brasileiro, especialmente a partir da clara definição das respectivas posições. "De um lado um estado ainda mais galicano, liberal e anticlerical e, de outro, uma Igreja que aparentemente abandona o confronto com o Estado, mas que toma medidas de auto-fortalecimento interno. O Estado monárquico era pombalino, josefista e regalista e seu Imperador era renanista e quem sabe se até voltairiano. Para ele o Estado estava acima de qualquer coisa" ${ }^{\text {18 }}$. Muitos intelectuais e políticos liberais aspiravam à instituição de uma Igreja nacional, só sujeita a Roma em questões de doutrina, sendo o Imperador a autoridade máxima na constituição da hierarquia e no julgamento de leis e decretos dos Concílios. Esse era o pensamento de Joaquim Nabuco ${ }^{19}$.

A força econômica da Grã-Bretanha mostrou-se especialmente influente na política. Já tinha conseguido a abertura dos portos brasileiros às nações amigas em 1808. Com a necessidade de imigração, pressionou o Império a proibir o tráfico de escravo, que crescera a tal ponto que a Grã-Bretanha impôs em 1810 a assinatura do tratado comercial, no qual o Brasil condenou o tráfico de escravos e aceitou sua restrição no hemisfério $\operatorname{sul}^{20}$, passou a administrar taxas alfandegárias inferiores para produtos britânicos em relação a produtos portugueses e "também a tolerar uma comunidade anglicana no exterior no Rio de Janeiro, a primeira comunidade não-católica em todo o território colonial espanhol-português" ${ }^{21}$. Isso abriu caminho para mudanças na legislação de imigração, desde a lei de 16 de fevereiro de 1813, que só previa a presença de católicos romanos, até que a Constituição de 1824, "redigida por Dom Pedro I, com a ajuda de seu Conselho de Estado sob a influência do espírito liberal-maçônico, concedeu no Art. $5^{\circ}$ a não-católicos o exercício privado, enquanto o exercício público da religião - à semelhança do que consta na Patente de Tolerância Josefina de 1781 - ficou reservada à Igreja Católica Romana como guardiã da religião do Estado"22.

\footnotetext{
${ }^{18}$ VILLAÇA, A. C. História..., p. 27 apud MENDONÇA, A. G. Op. cit., p. 229. Liberal: que tem idéias ou opiniões avançadas, amplas, tolerantes, livres ou adota a doutrina liberal. Pombalino: referente ao estadista português Sebastião José de Carvalho e Melo (1699-1782), o Marquês de Pombal.

${ }^{19}$ VILLAÇA, A. C. História..., p. 146 apud MENDONÇA, A. G. Op. cit., p. 229.

20 "Um passo adiante deram as convenções de 22/10/1815 e 28/07/1817 com artigos adicionais de 11/09/1817, que instituíram o direito de inspeção mútua... sujeitou-se à exigência de que, três anos após a retificação (23/03/1827), o tráfico negreiro africano fosse totalmente abolido e equiparado à pirataria... até que uma lei imperial de $07 / 09 / 1850$, de fato, pôs fim à importação de escravos". SCHRÖDER, F. Brasilien und Wittenberg. Berlin: 1936, p. 27.

${ }^{21}$ PRIEN, H.-J. La Historia del Cristianismo..., p. 33.

${ }^{22}$ Ibid. O teor do Art. $5^{\circ}$ : "A religião católica apostólica romana continuará ser a religião do império. Todas as outras religiões serão permitidas com seu culto doméstico ou particular, em
} 
O quadro propício à penetração do protestantismo logo se configurou. Surge um vácuo religioso, no qual de um lado, está um Estado em busca de uma religião civil aberta, e de outro, a Igreja que, diante da possibilidade de perder suas prerrogativas, volta-se para si mesma com a intenção de reforçar-se institucionalmente. No meio ficou um espaço aberto, pelo qual o protestantismo penetrou. $\mathrm{O}$ conjunto das expectativas da sociedade deram a contribuição restante. $\mathrm{O}$ comércio inglês, a agricultura germânica, a possível vinda de imigrantes confederados norte-americanos acenaram com um surto de modernização e progresso, sem maiores riscos políticos e a possibilidade de assimilar as idéias e práticas que fizeram dos anglo-saxões os líderes do mundo da época. A abertura para o mundo anglo-saxão significou abertura para o universo protestante ${ }^{23}$.

\section{Da propaganda do Império às colônias de imigrantes}

O protestantismo de imigração é o que se desenvolveu a partir do movimento imigratório que marcou o século XIX, seguindo as ondas de intensidade e retração. O projeto imigratório associado ao elemento étnico e religioso lhe dá características próprias, inclusive impondo ao imigrante a difícil tarefa de adaptação, especialmente nos aspectos ideológico e religioso. Ao mesmo tempo, esses elementos representam um fator de coesão do grupo e lhe atribuem uma identidade num ambiente geográfico, climático, cultural, econômico, político e religioso inteiramente estranho e por vezes adverso ${ }^{24}$.

O processo de adaptação e tolerância, incluindo a religiosa, já estava condicionado "pela necessidade de mão-de-obra por parte dos países receptores dos imigrantes, onde o catolicismo era a religião hegemônica, quando não oficial", observa-se, especialmente entre os grupos que têm "na preservação da cultura e, especialmente, na preservação do idioma uma das suas características fundamentais" $" 25$. Essa perspectiva de dupla diáspora, simultaneamente uma diáspora religiosa e outra étnica, colocam o risco "de que a consciência étnica de diáspora se sobreponha à consciência eclesiástica, ou

casas para isso destinadas, sem forma alguma exterior de templo". Constituições do Brasil. Rio de Janeiro: Imprensa Nacional, 1948, p. 35.

${ }^{23}$ MENDONÇA, A. G. Op. cit., p. 230.

${ }^{24}$ WIRTH, L. E. Protestantismo e etnia: sobre a preservação da identidade étnica no protestantismo de imigração. Estudos Teológicos/EST 1998/38 (2): 157.

${ }^{25}$ Ibid., p. 157-8. 
que o serviço da diáspora por parte da Igreja seja entendido como assistência étnica" 26 .

O problema essencial no processo de formação da Igreja evangélicoalemã no Brasil está presente desde os primórdios. Em outras circunstâncias, "com as novas gerações, nascidas nos países de imigração, constata-se um processo de aculturação que se evidencia na independência institucional, na adoção do idioma nacional, no engajamento social, no desenvolvimento de estratégias para conquistar adeptos entre a população autóctone, um processo que geralmente vem acompanhado por uma crise de identidade, por estagnação ou por crescimento apenas vegetativo" ${ }^{27}$. A mesma coisa pode ser dita da "relação entre religião e etnia a partir dos espaços concretos de articulação da vida, percebe-se uma flexibilidade e dinamicidade tanto da religião quanto da etnia, de acordo com as demandas locais", levando à compreensão "que a identidade étnica era um fator conjuntural, entre outros, no cotidiano dos imigrantes, um elemento que tendia a se diluir na medida em que o imigrante $\mathrm{e}$, principalmente, seus descendentes se integravam à sociedade envolvente" ${ }^{28}$.

As principais motivações para a imigração foram efetivamente "a miséria econômica e a superpopulação, em proporção diferente nos diversos territórios alemães", tendo como fator desencadeador "o inverno de fome de 1816/17 no sudoeste alemão. Os anos de 1816-1825 designam simultaneamente uma fase de extremo crescimento populacional, que levou a um índice médio de crescimento anual de $1,42 \%$, o mais elevado de todo o século XIX, referente ao futuro território do Reich de $1871^{\prime 29}$. O século XIX foi marcado pelas grandes migrações, com cerca de 10 milhões de alemães deixando seu país e 35 milhões de pessoas saindo da Europa para os Estados Unidos, somente entre 1860 e 1930, provocando, deste modo, a maior movimentação de habitantes. "A parcela dos que emigraram para o Brasil foi relativamente modesta. De 1815 até 1848 devem ter sido no máximo 15 mil pessoas, de 1850-1859: 15.815, de 1860-1895: 63.370. Os números efetivos são mais

\footnotetext{
${ }^{26}$ LAU, F. Evangelische Diaspora. In: Religion in Geschichte und Gegenwart. 3. ed. Tübingen: 1958, v. 2, col. 179 apud PRIEN, H.-J. Formação da Igreja Evangélica no Brasil. Trad. Ilson Kayser. São Leopoldo: Sinodal; Petrópolis: Vozes, 2001, p. 23.

${ }^{27}$ WIRTH, L. E. Protestantismo e etnia..., p. 157-8.

${ }^{28}$ Ibid.

${ }^{29}$ RÜRUP, R. Deutschland im 19. Jh., 1815-1871. In: Deutsche Geschichte. Göttingen: 1985, v. 3, p. 16 apud PRIEN, H.-J. Formação da Igreja..., p. 23.
} 
elevados, visto que a estatística brasileira se limita ao território do Reich

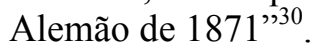

A presença de recrutadores brasileiros atuando em território alemão tem duas explicações: a ligação da dinastia de Habsburg com a casa real portuguesa e a posterior casa imperial do Brasil, a partir do casamento de D. Pedro com Dona Leopoldina em 1817, e a boa reputação dos alemães como colonizadores. Em razão disso, o início da emigração para o Brasil coincidiu com a primeira tentativa de povoamento com teuto-suíços neste mesmo ano em Nova Friburgo. A terra de matas virgens estimulou a fantasia dos imigrantes, especialmente em época com pequena circulação de informações. "A avalanche emigratória de 1816/17 espalhou-se desde a Alemanha Meridional, passando pelo Palatinado, até Trier, mas ainda se deteve diante da região do Mosela e da Renânia. Somente nos anos 20 ela transpôs o Mosela e adquiriu grande importância no Hunsrück pela campanha de recrutamento do major Schaeffer" ${ }^{31}$.

Chegados ao Brasil, houve certa freqüência na destinação dos emigrantes aos projetos de assentamento. Os pomeranos se estabeleceram no Espírito Santo, nas regiões de São Lourenço, Pelotas e Santa Cruz, no Rio Grande do Sul, e, com outros do norte da Alemanha, nas regiões de Joinville e Vale do Itajaí, em Santa Catarina. Os provenientes do Hunsrück e da Renânia foram para os arredores de São Leopoldo ${ }^{32}$ e dali para o interior da província de São Pedro do Rio Grande do Sul. Os originários da Westfália foram para Teutônia e Estrela, os sábios se dirigiram a Neu-Württemberg e os do Sudeto para Nova Petrópolis, e os teuto-russos (deutschrussisch) do Volga e da Rússia foram assentados em Palmitos e Cunha Porã, em Santa Catarina, em Witmarsum e Boqueirão, no Paraná, e em Bagé, no Rio Grande do Sul. Centros urbanos como o Rio de Janeiro, São Paulo e Porto Alegre atraíram comerciantes, estudiosos, médicos, engenheiros e técnicos entre os imigrados ${ }^{33}$.

\footnotetext{
${ }^{30}$ PRIEN, H.-J., Formação da Igreja..., p. 25. "O imigrante alemão no Brasil é parte de um processo de emigração em massa que, nos estados alemães, perdurou de 1815 até a Primeira Guerra Mundial. O Brasil recebeu cerca de $2 \%$ desses emigrantes, sendo que a grande maioria se dirigiu aos Estados Unidos" (cf. MARSCHALK, P., Deutsche Überseewanderung in 19. Jahrhundert. Stuttgart: 1973). Esse fenômeno é um dos aspectos das profundas transformações sociais ocorridas na Europa do século XIX, transformações essas que marcaram a transição da sociedade agrária para a sociedade industrial. WIRTH, L. E., Op. cit., p. 160.

${ }_{31}^{31}$ SUDHAUS, F., Op. cit., p. 51-56 apud PRIEN, H.-J., Formação da Igreja..., p. 27.

32 Decreto imperial de 22 de setembro de 1824 deu o nome de São Leopoldo à colônia, em homenagem à imperatriz Leopoldina, da dinastia de Habsburg, cf. FAUSEL, E. São Leopoldo: Statistische Ermittlung aus deutschen evangelischen Kirchenbüchern in Übersee. Volkstumsforschung, 1939/3 (3): 201-21.

${ }^{33}$ PRIEN, H.-J., Formação da Igreja..., p. 29.
} 


\section{O germanismo e a re-orientação teológica}

Esse processo de colonização não se deu de forma diferenciada apenas na origem do empreendimento, mas também na sua administração e, conseqüentemente, nos efeitos variados para as populações de emigrados. Para compreender o desenvolvimento dessas colônias e perceber o efeito que os novos fatos produziram para o surgimento do germanismo e seu conseqüente impacto na vida do que viria a ser a Igreja Evangélica de Confissão Luterana no Brasil é preciso considerar a perspectiva recente de Lauri Wirth. É necessário "relativizar a centralidade do fator étnico como decorrência natural da conjuntura dentro da qual o protestantismo de imigração se desenvolveu" ${ }^{34}$. Argumenta que o imigrante alemão não possuía uma identidade nacional, baseado no fato de que esta só surgiu com a unificação dos territórios alemães ocorrida em 1871, quase 50 anos depois da chegada ao Brasil dos primeiros imigrados.

Para Wirth, os imigrantes traziam as culturas dos locais de onde eram oriundos, que essas culturas eram distintas, não manifestando coesão étnica e tendo muitos elementos de diferença. Esse aspecto se mostra evidente no uso da língua, já que entre poucos imigrantes falavam alemão clássico (Hochdeutsch), mas os dialetos regionais. Por razões que envolviam dominação cultural, imigrantes da Pomerânia chegavam a referir-se ao alemão clássico como 'língua estrangeira' tal qual a língua portuguesa. Outra intenção é descobrir a razão pela qual em algumas igrejas resultantes do protestantismo de imigração, o processo de aculturação se deu de maneira mais rápida, mesmo sob condicionantes locais semelhantes.

O debate sobre a presença dos imigrantes alemães conduz, invariavelmente, à discussão sobre o papel da religião em sua vida e dos desdobramentos que este assumiu em solo brasileiro. De maneira geral, "o imigrante tinha vínculos frágeis com as instituições religiosas, não pertencia ao 'núcleo fiel' das mesmas e estava pouco familiarizado com suas estruturas de poder. Portanto, é pouco provável que os imigrantes reproduzissem espontaneamente os modelos de poder religioso de seus países de origem. Aliás, sua indiferença, senão sua aversão, diante de tal poder, principalmente nos espaços urbanos emergentes, é uma das queixas mais cortantes de missionários e teólogos que seguiram os imigrantes com a incumbência de implantar uma Igreja"35.

\footnotetext{
${ }^{34}$ WIRTH, L. E., Protestantismo e etnia..., p. 159.

${ }^{35}$ Ibid.
} 
Conquanto a Igreja estivesse presente, formal e informalmente na vida dos emigrados ${ }^{36}$, foi em círculos políticos alemães que a preocupação com os imigrantes, em discurso com roupagem nacionalista, começou a crescer. "Esses colonos continuarão tendo muita afinidade com os alemães de aquém-mar devido à língua, ao modo de vida, aos usos e costumes e, por isso, preferirão relacionar-se com estes do que com outras nações européias, se as demais circunstâncias forem relativamente semelhantes. Entre os alemães dos dois hemisférios estabelecer-se-á um relacionamento semelhante ao que existe entre a Inglaterra e suas colônias na América do Norte, e a Alemanha não continuará sentindo a falta de colônias como privação",37.

É importante não perder de vista que desde a chegada dos imigrantes até a revolução alemã (1848) passam-se apenas 24 anos, quando começa o processo de mercantilização da imigração. E que 40 anos após esse período é assinada a lei da abolição da escravatura, a partir da pressão da Inglaterra. A primeira constatação é que o imigrante se torna uma necessidade na economia à medida que substitui o escravo e sua força de trabalho. A segunda é que as elites econômicas brasileiras se comportavam de maneira tão ensimesmada e tão pouco preocupada com qualquer outra coisa que não fosse a preservação dos seus privilégios, que insistem na convivência da escravatura e da mão-de-obra dos imigrantes por 64 anos.

A partir da segunda metade da década de 1930, o presidente do Sínodo Rio-Grandense, Pastor Hermann Dohms passou a ter a colaboração do teólogo que deu significativa contribuição no atenuamento dos efeitos da teologia etnicista, Ernesto Theóphilo Schlieper ${ }^{38}$. Os reflexos da contribuição teológica de Karl Barth logo se mostraram através da sua perspectiva teológica e

\footnotetext{
${ }^{36}$ Através da presença do Pastor Friedrich Oswald Sauerbronn, que chegou em 31/01/1824 na fragata holandesa Argo à Armação das Baleias em Niterói, trazendo 251 imigrantes alemães e suas mulheres e 29 homens para o serviço militar no Brasil, chegando à Nova Friburgo em 02 de maio, segundo os dados do 'Diário de Governo'. Em 13/04/1824 aportou a fragata Carolina, trazendo 162 homens, 16 mulheres e 51 crianças. Em 04/06/1824 chegou à fragata Anna Luise com 269 homens, 16 mulheres e 40 crianças, que seguiram para a Província de São Pedro e chegaram em 25 de julho como os primeiros colonos de São Leopoldo. E também através da expressão de fé dos luteranos da Pomerânia, que mesmo "no período de maior abandono eclesiástico, jamais se poderia ter tirado dos nossos pomeranos seu catecismo luterano e substituí-lo por outro. Nenhuma família pomerana havia saído da pátria alemã sem empacotar, como maior patrimônio, a Bíblia, o Hinário ou algum outro antigo consolador". SCHLÜNZEN, F. Lutherthum in Brasilien. Jahrbuch des Martin-Luther-Bundes, 1951-52, p. 97.

${ }^{37}$ WITT, O. L. Igreja na migração e colonização. São Leopoldo: Sinodal, 1996, p. 22.

${ }^{38}$ Aluno de Karl Barth na Universidade de Bonn desde 1931, Schlieper descobre ser impossível tornar-se pastor para preservar a germanidade. Ibid., p. 130.
} 
dos debates e posicionamentos que marcaram o período anterior e posterior à Segunda Guerra, o momento de maior impacto para reorientação teológica dos Sínodos e da Federação Sinodal.

O trabalho teológico de Schlieper foi exigente e intenso, mesmo sem ter total clareza do destino histórico que lhe estaria reservado, de ser um dos principais atores da reorientação teológica no Sínodo Rio-Grandense. A influência da perspectiva teológica de Karl Barth não surgiu apenas de forma indireta, através das suas aulas, mas também numa resposta à carta enviada em novembro de 1933 pelo pastor Heinz Giessel, de Santa Maria da Boca do Monte (RS), para o eminente teólogo suíço, a quem tinha ouvido durante suas férias em Berlim, na Alemanha.

Giessel reflete a já inquietante posição de alguns pastores alemães no Brasil, para quem tornava-se cada vez mais insustentável a manutenção de uma estrutura teológica com claras limitações para o futuro da Igreja. Ele dirige-se ao eminente teólogo para indagar: "Que acontece com a nãorelacionalidade da fé com o etnicismo em nossa Igreja Evangélica Alemã no Brasil? (...) teria nossa Igreja de lá pecado todos esses anos, quando se deixou guiar pelo Evangelho exclusivamente para a preservação do etnicismo alemão? Acaso nós pastores, considerados os únicos portadores culturais daquelas colônias alemãs no exterior, não pecamos gravemente, quando, no além-mar, nos inserimos nas sociedades alemãs e lhes pregamos a preservação da índole e dos costumes alemães como ordenado por Deus?" ${ }^{39}$. Suas dúvidas, eminentemente teológico-pastorais, traduziam os reais dilemas dessa teologia para a realidade das comunidades luteranas no Brasil do segundo quartel do século XIX.

Barth responde, em estilo pastoral, que "tudo que foi dito sobre a singularidade da revelação, sobre a liberdade do Evangelho e a soberania da fé vale, naturalmente, também e de modo especial na construção tão singular das comunidades dos países limítrofes e do exterior”. Já aqui Barth afirmou que comunidades luteranas teuto-brasileiras em nada se diferenciavam, do ponto de vista da salvação, de outras comunidades cristãs de qualquer outro lugar. Ponderou que era uma comunidade brasileira composta de alemães e essa era uma dificuldade especial. "E para o senhor e sua comunidade somente pode significar um ganho, se têm tão clara consciência disso. O senhor não deve nem pode ignorar por um momento sequer o dado fundamental de sua vida na comunidade: que sua gente são alemães e que existe o

${ }^{39}$ Com a publicação anônima dessa correspondência no Theologische Existenz Heute, v. 5, 1933, p. 20-4, iniciou-se nova etapa do debate sobre a teologia etnicista no Brasil. ap PRIEN, H.-J. Formação da Igreja Evangélica..., p. 377. 
justificado desejo de que seu germanismo lhes seja preservado"40. Barth não diz ser impossível a expressão da fé através dos valores de uma cultura, embora também não condicione aquela a esta, ao mesmo tempo que compreende a necessidade de preservação da expressão cultural.

"Sua dificuldade especial consiste no fato de que, por assim dizer", afirma Barth, "o senhor tem que ser, em união pessoal, representante do germanismo e representante do Evangelho". Após ponderar sobre a dificuldade da situação, insiste que eles têm que "dialogar constantemente consigo mesmos: ora o alemão falando com o pastor, ora o pastor falando com o alemão (...) só que uma coisa lhes tem que estar presente: não é o alemão que tem que dirigir este diálogo, e, sim, o pastor, que, por assim dizer, deve assumir e desempenhar nele o papel de Sócrates"41. A tarefa atribuída ao pastor, de condutor do diálogo, é ajudar os colonos alemães a defrontarem-se com a verdade, que muitas vezes não possui bom aspecto, além de não pertencer ao mundo das aparências. Talvez tenha querido o teólogo suíço orientar a ênfase para o "conhece-te a ti mesmo", sem querer que os pastores se arroguem o direito de ensinar sobre a natureza humana, mas apenas que se disponham a ajudar a refletir, a tomar consciência dos próprios pensamentos e a trazer à luz o que já têm em si mesmos ${ }^{42}$.

Com o necessário distanciamento crítico e sem o envolvimento emocional e comunitário dos pastores que atendiam comunidades alemãs no "exterior", Barth observa que "como a pessoa irreconciliada, cega, pecadora que ela é, e, não obstante, aceita na Igreja do Senhor com toda a sua existência - o pastor, porém, tem o dever de anunciar a contrapergunta e a contraresposta da palavra de Deus com base no primeiro, segundo e terceiro artigos da fé" ${ }^{43}$. A tarefa pastoral deve começar no que é mais básico: a condição de pessoa humana, aceita na comunidade de fé e em interlocução com a palavra de Deus, a partir da comunhão.

Entre os deveres do pastor está o "de entender o bom alemão melhor do que ele entende a si mesmo, terá que aceitá-lo, portanto, em toda a sua germanidade (o que também pode significar que o senhor, em nome de Deus, ministre aulas de alemão, cante canções folclóricas alemãs com sua gente, ensine-lhes história alemã e o que mais entrar em cogitação)" "44. Isso significa acolhê-lo pastoralmente no conjunto de sua condição humana (sua

\footnotetext{
${ }^{40} \mathrm{Ibid}$.

${ }^{41}$ Ibid, p. 378.

${ }^{42}$ VERGEZ, H. e HUISMAN, D. História dos filósofos. Trad. Lélia de Almeida Gonzalez. 4. Ed. Rio de Janeiro: Freitas Bastos, 1980, p. 26-7.

${ }^{43}$ PRIEN, H.-J. Formação da Igreja Evangélica..., p. 378.

${ }^{44}$ Ibid.
} 
origem étnica, sua bagagem cultural, sua situação de vida, sua condição social). Mais deverá interagir com essa condição para ajudá-lo a integrar-se à vida no ambiente em que está. Ao saber que lida com uma pessoa marcada por rupturas e adaptações traumáticas, deve fazer o esforço necessário para atenuar esse impacto, estimular uma resposta comunitária às necessidades desta pessoa e fazer uma abordagem aproximativa de sua realidade.

Continua Barth, "no entanto, de modo explícito ou implícito, nisso e com isso tudo deve recebê-lo na comunhão dos santos, e, portanto, entender novamente todas as manifestações de seu germanismo, de nenhum outro modo senão como uma confissão abrangente do pecador alemão, ao qual deve anunciar a absolvição, pois para isso ele é propriamente e em primeiro lugar pastor no Brasil (...) ${ }^{345}$. Deve ter rosto eclesial, ser uma presença que traduz o vivo interesse de Deus em seu bem-estar, já que não pode arrogar-se a falar em nome de uma instituição financeiramente forte. Acolher na comunhão dá identidade de fé, fortalece a identidade doutrinal e anima na estruturação da própria identidade, no sentido psicológico. Ouvir a confissão e anunciar a absolvição possibilita a experiência da comunhão com Deus e empresta sentido à presença pastoral da Igreja.

Lembra ainda o teólogo de Basiléia, que "a verdadeira prevalência do primado da palavra de Deus naturalmente é assunto da própria palavra e somente dela, e por isso o senhor não deve criar escrúpulos em todo esse assunto. Se o senhor estiver na fé e na obediência, que aconteça aquela desgraça cá e lá - como, aliás, cá e lá acontece grande desgraça em nosso fazer, mesmo na melhor vida - e por fim tudo servirá ao bem para o senhor e sua comunidade". Talvez movido pelas pressões do crescente nacionalsocialismo, ele anima o pastor, por vezes também em condições precárias de vida e trabalho, a confiar que a palavra anunciada tem sua própria força, que não está condicionada à sua aparente fraqueza e que o poder de Deus se aperfeiçoa em sua fraqueza humana (2 Co 12.9).

E concluiu: "Portanto (...) ataque com firmeza seu inevitável trabalho em favor do germanismo, pecca, pecca fortiter ${ }^{46}$ !", manifestando a esperança de que a carta não seja mostrada a um teuto-cristão, "que dele - quem sabe? - iria sorver um mel que não foi coletado para ele" ${ }^{" 47}$. O conselho para pecar com força neste contexto, levantava a questão sobre a necessidade de atendimento ao grupo e sobre as possibilidades de acerto, sem referir-se ao papel da Igreja como fomentadora da cultura germânica.

\footnotetext{
${ }^{45} \mathrm{Ibid}$.

${ }^{46}$ Peca, peca com força!

${ }^{47}$ IBID.
} 
A publicação da carta de Barth no informativo Theologische Existenz Heute (Existência Teológica Hoje) teve impacto imediato como tema de debate teológico na Europa, chegando com efeito retardado mas eficiente ao trabalho dos Sínodos Evangélicos no Brasil, apesar de seus efeitos serem ainda ignorados pela pesquisa ${ }^{48}$. A influência desta reorientação teológica começou a alterar a perspectiva de ser Igreja dos imigrantes alemães que, passa da sua auto-compreensão como "esteio da cultura germânica" para a de "Igreja no Brasil", especialmente após o impacto da Segunda Guerra Mundial.

Para buscar o sentido fundamental e absoluto da presença da Igreja luterana em terras brasileiras, Westhelle recorre a Hegel, "um luterano absolutamente convencido de que o fundamento da religião não estava nem no sentimento, nem na espiritualidade, mas no ser de Deus mesmo, na Idéia absoluta que na religião toma corpo como um momento de realização de sua própria liberdade", estabelecendo que "a religião é o relato, a documentação externamente disponível da realização da natureza de Deus mesmo. Não é pelo sentimento humano, mas pela realização do próprio Deus na história que a religião existe. E a teologia torna-se esta ciência que articula, discerne, e examina estas máscaras de Deus deixadas na história na forma de linguagem religiosa, as representações que povoam o imaginário religioso do povo, seus mitos, ritos, lendas e estórias" 49 .

Antonio Carlos Ribeiro

Doutorando em Teologia pela PUC-Rio

\footnotetext{
${ }^{48}$ Ibid., p. 379.

49 WESTHELLE, V. Uma fé em busca de linguagem; o sedicioso charme da teologia na IECLB. Estudos Teológicos/EST 1992/32 (1): 69.
} 